\title{
Trunk road A82: the Loch Lomondside road: conception to implementation
}

\author{
J. A. Howison and A. Macdonald
}

\section{Mr Howison and Mr Macdonald}

Since the original Paper was written, the second of the major contracts on the Luss to Hollybank length of the A82 improvements has begun. The $£ 8.3$ million contract for $6.4 \mathrm{~km}$ of improvement between Luss and Camus nan Clais was awarded to Shanks \& McEwan Limited. Two particular aspects of this work are worthy of further mention.

61. Firstly, traffic handling during construction had been the subject of discussions with the local authority at the scheme promotion stage, as described in the Paper. Only $1.2 \mathrm{~km}$ of the existing road are unaffected by the works, as traffic diversions to maintain two-way traffic at all times are required elsewhere. The Specification for these diversions calls for a $6 \mathrm{~m}$ minimum width of bituminous surfaced carriageway with safety fencing to full highway standards on all the lochside diversions. Diversions to this standard were in operation during the 1988 summer tourist season and delays were kept to a minimum with no noticeable diversion of traffic to other routes.

62. Secondly, on the majority of the deepwater embankments, recorded movements since completion of construction had virtually ceased by the start of the Luss to Camus contract, thus allowing roadworks to continue. However, the southern section of Wades Bridge Bank, where major displacements occurred during construction, continued to give cause for concern. Steady lateral and vertical movement was continuing and so the placement of a $2.5 \mathrm{~m}$ surcharge load was instructed. This had an immediate effect of accelerating movement, which then gradually decreased to acceptable levels to enable final construction to continue. As an added precaution against reflective cracking on the carriageway surface, caused by differential settlement, two layers of a polymer geogrid will be incorporated in this and all other lochside embankments where they partly overlie the old road and its lochside retaining walls.

\section{Mr C. Hood, Engineering Management Group Board}

A great number of visitors to Loch Lomond come from Glasgow and the surrounding towns, which indicates that the area is more than a tourist attraction.

64. My first question concerns the gestation period of the project. Initially, reference was made to a gestation period of 15 years: is it possible to split this 15 year period between design and consultation with the various authorities and the initial feasibility studies? I know that such procedures take a great deal of time, but the public is generally not aware of that. The second question relates to the site 


\section{DISCUSSION}

difficulties mentioned in paragraph 58. Could it be argued that these arose because site investigations were not adequate or sufficient enough to be really informative? Or are the Authors inclined perhaps to think as I do: the worst is discovered only after the hole has been dug? Would the Authors please expand on this subject?

\section{Mr A. W. Shilston, Consulting Engineer}

I should like to raise four points: three of a management and one of a technical management character.

66. My first point relates to the continual up-dating of the forecast cost or rather the likely price for this scheme, which must have been a difficult task. Did the designers approach this from the standpoint of analytical estimating or did they apply the somewhat traditional quantity surveyor's approach of relying on old tenders? I offer an answer to this question by suggesting that, in the absence of precedent and because of the unusualness of this scheme, it would not be appropriate to apply historical rates in the pricing which had been derived from previous dissimilar schemes.

67. My second question relates to a sentence in the last paragraph of the Paper: 'During construction, site difficulties, known and unknown, have had to be met and further requirements of the project accommodated.' Mr Hood has touched on this point, but I refer to it in the context of valuing the work. In a scheme such as this, valuing changed work must be very difficult, particularly if there exists a traditional priced bill of quantities. In American practice, as I understand it, bills of quantities are not used. When work is changed extensively, as quite clearly this work was (as indicated in the Paper), I imagine the usual American approach to valuing changed work, in the absence of bills of quantities, is to cost it out on a first principles basis by reference to actual cost, to which overheads and mark-up are applied. Valuation of varied work by reference to priced bills of quantities would be extremely difficult to achieve in the particular job. What did the Authors or the designers do in valuing changed work, and have they any thoughts as to how they might approach this task on a similar scheme? I am inviting the Authors to comment on the suitability of pricing changed work, on this contract, by reference to the extant priced bill of quantities.

68. The next point I should like to raise concerns the procedure for opening tenders. The impression I get from reading the trade journals is that on overseas work it is usual for tenders to be lodged by noon, and then two hours later there is a public opening of tenders. I have often wondered why this procedure is not adopted in the UK. In the building sphere, in particular, it was quite usual not so long ago to invite tendering contractors to attend a bid opening ceremony. However, this practice seems now to have disappeared, even though it was a sound idea; it is recommended good practice in a well-known UK textbook. ${ }^{12}$ In Scottish Development work, is it invariably the practice to publish the outcome of the tender bidding, without of course naming names, soon after the arrival of bids?

69. Finally, I had assumed that in this particular scheme it went without saying that this would be a flexible construction carriageway. However, might I ask the general question: would it be ruled out entirely that the traditional approach (at least in England) of going out to tender on a black top and concrete paving basis would not apply in that particular part of Scotland? I have in mind that a dominant reason for using black top is that, in an environmentally sensitive area, it would be less offensive to the eye than the colour of concrete. 


\section{Dr M. P. O'Reilly, Transport and Road Research Laboratory}

There are two notable aspects in the contract from Camus to Hollybank and both are related to the Rubha Mor cutting. The first is the unusual ploy of using the surplus excavated rock on one contract to provide advanced earthworks on the subsequent contract. The second is the rock excavation itself and the sculpting of a presplit rock face in mica schists - highly discontinuous rock types which have been regarded by many as not suitable for presplitting. There is no doubt that there is a great deal to learn from the work that has gone on in Scotland over the last 10-15 years on the application of presplit blasting techniques to the excavation of highway cuttings.

71. Basically, presplitting consists of using explosives to produce a discontinuity between the rock to be excavated and the rock that is to remain. The presence of this discontinuity enables the gases produced in the main bulk blast to vent and escape at the sloping boundaries of the proposed excavation; the rock that is to remain in place is thus protected from damage. This leaves the natural rock undisturbed; stability is not adversely affected; and subsequent maintenance is minimized.

72. A striking example of the type of cutting produced by bulk blasting alone is the cutting, in dolerite, to the north of the Forth Road Bridge on the A90. As can be seen in Fig. 12, this has left the sides of the cutting in a fractured and loosened state which has required considerable and continuing maintenance over the years.

73. On the other hand, the cutting on the M90 at Moncrieffe Hill (Fig. 13), where Babtie, Shaw and Morton were again the consulting engineers, shows how presplit blasting produces an excellent final face. As can be seen, there are two basaltic lava flows, and while presplitting has dealt effectively with the rock faces themselves, masonry is being placed to protect the easily weathered pyroclastic material between the flows.

74. Presplit faces characteristically show a parallel pattern of half-barrels remaining from the holes used to place the presplit charges. Some argue that such regularity is unattractive but at least it does show the passers-by that engineers knew what they were doing when forming the cutting.

75. The undoubted success of this project results from the successful marriage of theory and practice. It stands as an example to client and engineers of the importance of geotechnical engineering in modern road building. In particular, the design and construction of the rock slopes are of the highest standard and other engineers both nationally and internationally would do well to follow their example.

\section{Mr J. W. Morrison, Ritchies Equipment}

We did the drilling and blasting on Loch Lomondside. In $\S 70$, Dr O'Reilly refers to the Rubha Mor cutting; here the presplit holes were found to bend into the bedding planes in what is termed an 'up-dip deviation'. It is difficult to do anything about such a deviation and yet the specification does call for the deviation at the bottom of the presplit hole not to exceed $300 \mathrm{~mm}$ from the design position. In practice, this up-dip deviation, combined with the other gravity induced deviation, did provide an aggregate deviation of up to $2 \mathrm{~m}$.

77. Is it possible to adjust the actual angle of drilling at the top in order to arrive at the bottom within specification and still not upset the geotechnical aspects of the cut? 


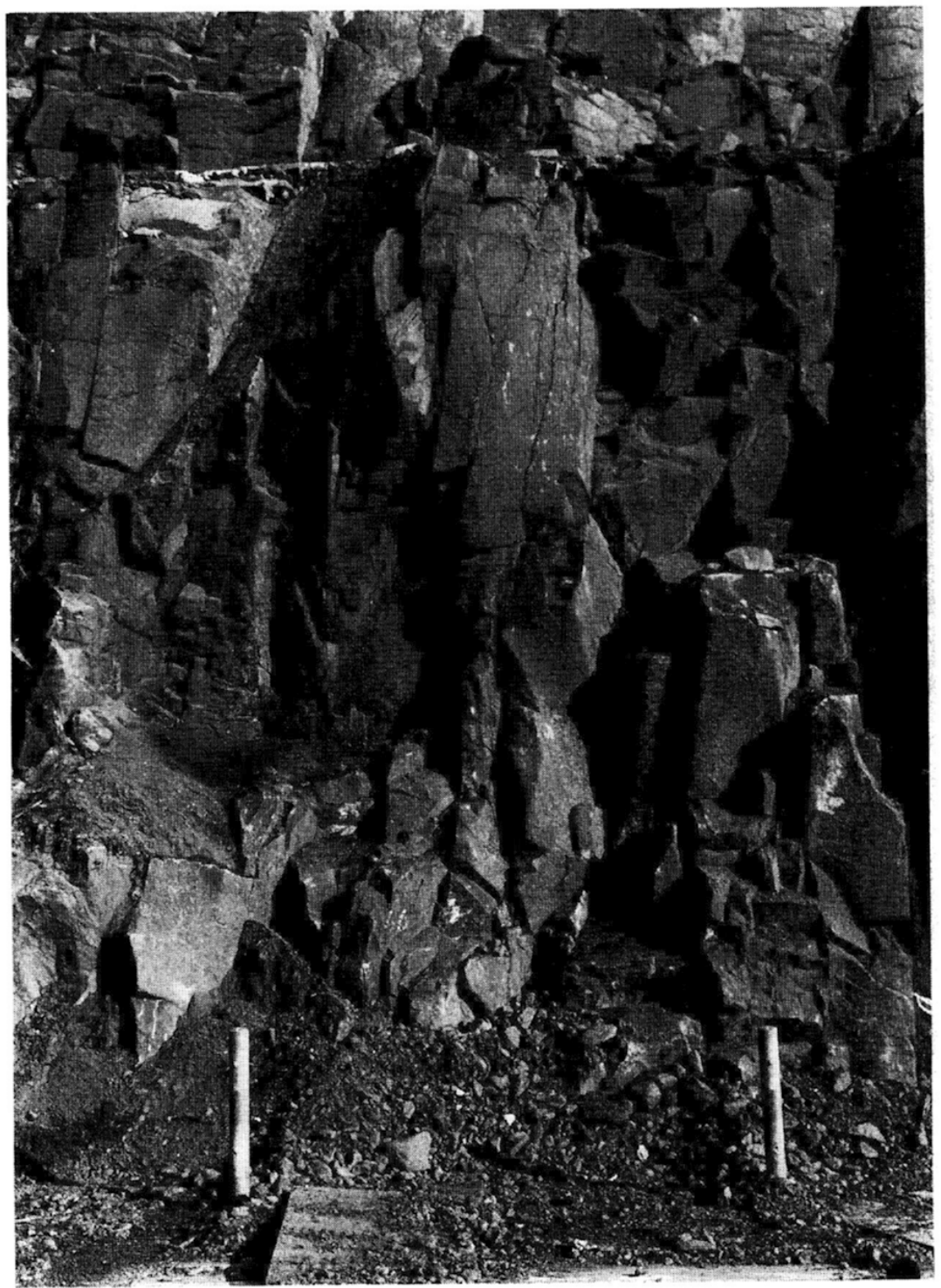

Fig. 12. Bulk blasting: A90 rock cutting north of Forth Bridge 

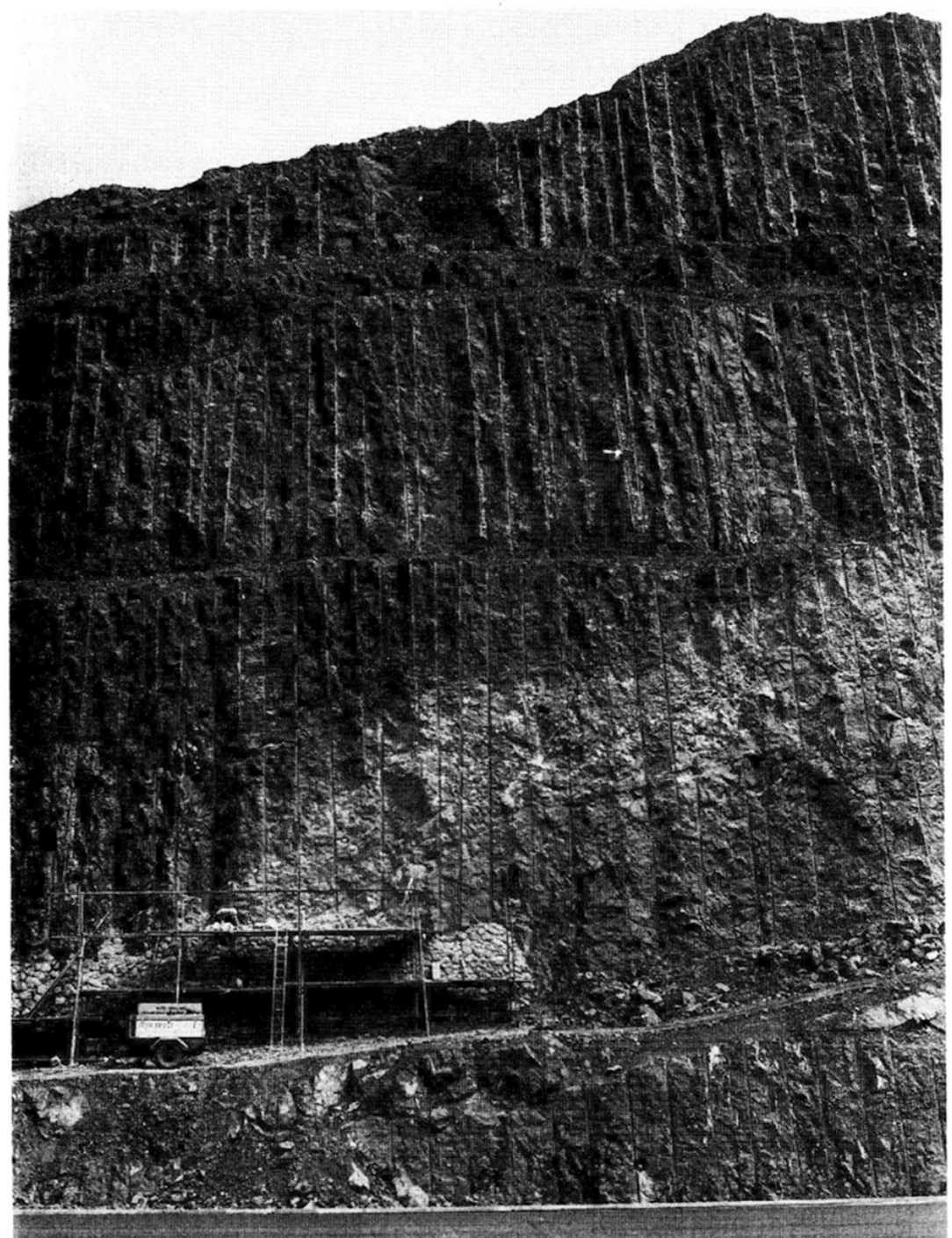

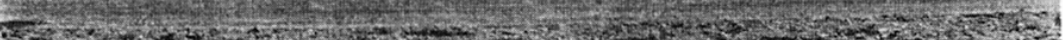

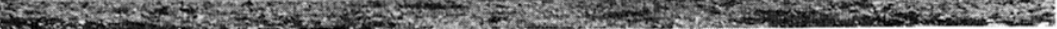

Fig. 13. Presplit blasting: M90 at Moncrieffe Hill 


\section{DISCUSSION}

\section{Mr R. Park, Babtie, Shaw and Morton}

I was resident engineer on the contract and while it is true that some of the presplit holes deviated off line by curving into the face, not all of them did so. In any one area an examination of the holes revealed that they remained parallel with each other, which was what was required for a good presplit face. I doubt if any hole was out of tolerance by as much as $3 \mathrm{~m}$.

\section{Mr. J. D. McKerracher, Tractor Shovels Tawse}

I was involved as the Contractor on the Loch Lomond contract and also on the earlier contract at Calvine.

80. The presplit works at Calvine was in the early days of presplit operations. The particular split at Calvine was caused primarily by the fact that we were using drifter drill rigs rather than the down-the-hole hammer rigs which are now specified in the contract. This emphasized the banana effect of these holes which obviously deviate into the planes in the rock, and this is much easier to control now with the use of down-the-hole rigs.

\section{Mr J. Carson, Miller Construction}

With regard to concrete, we have looked at pricing in Scotland and have never succeeded in getting a price that matches the black top price, for all sorts of reasons. I suggest that concrete would be viable only for dual carriageways and motorways, and for this reason would not be competitive in the type of construction we are discussing.

82. Did the Authors consider the quality of material? After blasting, the material is of a very mixed type, and I would think that some of it is subject to degradation by water. The integrity of the lochs down to the embankment will depend on the quality of the material, which must therefore be high.

\section{Dr D. J. Coats}

I was interested to read that this rock fill, which was placed in depths of water up to $36 \mathrm{~m}$, was carried out so satisfactorily on silt, aluvium and so on, on which it was placed. What monitoring of the actual placing was done? Was the fill going in the right place? Was it to the right profile and, if not, how was it corrected to the right profile? At what intervals were checks made of how it was progressing?

84. Loch Lomond is an area of environmental concern, and the new road has attracted a lot of comment. Rock anchors and rock dowels were used in the high cut. Could the Authors tell us the lengths of these and whether the end plates are obtrusive or may become so?

\section{Mr Howison and Mr Macdonald}

$\mathrm{Mr}$ Hood raises two questions, one relating to the scheme gestation period and the other to the adequacy of the site investigation. During the long gestation period for this project, the country experienced the oil crisis and the resulting period of recession in the early 1970s. There was also an emphasis on developing the A9 as an east coast route to the Scottish Highlands and it was not considered that two routes to the Highlands should progress in parallel. It was the promoter's own strategic decision which led to the 15 year period. The Orders for the Luss to Hollybank section were published in 1979, but much of detailed design started only in 1982, when the project was redesigned to accord to highway link standards 
and the final site investigation was undertaken. The time taken to engineer the project, once the commitment to this particular route was made, was fairly short.

86. In respect of the adequacy of the site investigation, we do not consider that more extensive investigations would have highlighted the problems encountered during construction. The extensive investigations on the loch bed had indicated the presence of organic silts and clays, and the philosophy behind the design approach was to attempt to displace these by loading the surface of the bed. The major displacement at Wades Bridge Bank was only unexpected in the manner in which it occurred, with sudden failure taking place after a considerable quantity of fill had been placed, compared to the more steady displacements on the other embankments. More extensive pre-contract investigations would not have changed the design approach in this area.

87. Similarly, on the Rubha Mor rock cutting, the true extent of the loose rock on the surface became evident only when borehole cameras were used to investigate the area during construction. While pre-contract boreholes in this area were limited in number on account of access difficulties, a thorough joint mapping survey had been carried out. Neither of these methods of investigation indicated a major zone of broken rock, rather that the rock was sound and competent. We consider that it would have required major additional expenditure at design stage to highlight these problems; expenditure which did not seem justified on the basis of the evidence of the investigations carried out.

88. Mr Shilston raises a number of points of interest in relation to the financial management of the work and environmental issues affecting the choice of surfacing material. With regard to the scheme estimate for the Camus to Hollybank contract, we can confirm that historic rates were used for estimating the majority of the items; a good indication of potential rates had been obtained from work undertaken locally, including the smaller trial embankment contract. However, this did not apply to the deepwater embankment filling where an estimate was prepared from first principles based on the assumption that fill would be placed by barge. The Consultant's pre-contract estimate was within $£ 30000$ of the lowest tender received. We would conclude from this that relying on recent prices for work done in a locality and in similar circumstances is a fair way to price estimates.

89. In respect of valuing changed work on the Camus to Hollybank contract, it would be inappropriate to answer this in detail at present as the measurement and final account is not yet completed. However, we can confirm that a Variation Order was issued for the stripping back of the large slabs of rock at Rubha Mor, payment being made on a daywork basis with agreed plant rates, as there was no easy way of measuring this work by other means.

90. Within the Scottish Development Department (SDD), tenders are opened in private and are reviewed in entire confidence, without any of the contractors knowing their competitors' prices. The Engineer reports on the tenders. The SDD writes, at the same time, both to the successful tenderer to award the contract and to the other tenderers to inform them that they have not been successful. The contractors' names are listed alphabetically, with tender totals given in ascending price and thus unrelated to name. The pre-announcement consideration is carried out with the utmost secrecy, so if any post-tender clarification is necessary, it is not done with the public knowledge of the competitors' prices. However, the SDD are considering this particular problem at the moment, recognizing that attempts at secrecy are generally not entirely successful. 


\section{DISCUSSION}

91. The colour of concrete is an interesting subject. When the Landscape Advisory Group was informed of the possibility of concrete surfacing, they voiced genuine concern. However, this was not the principal reason for specifying flexible construction. The overriding concern was the long-term settlements which may well occur in the lochside embankments. In fact, the section which was constructed around 1968, just south of Tarbet, is continuing to move even now. The rate no longer causes concern and can be accommodated within the normal resurfacing frequency, but in those circumstances it was considered essential to avoid any additional problems which a concrete pavement could bring. Our experience in respect of the economics of flexible against rigid construction in Scotland is similar to that of $M r$ Carson ( $(81)$, the latter having proved cheaper on only a small number of motorway schemes.

92. The views expressed by $\mathrm{Dr} \mathrm{O}^{\prime}$ Reilly are welcome, as we would agree unreservedly with his general comments on the benefits of presplitting for highway cuttings in hard rock. Presplitting is costly-i.e. in the order of $£ 6-7 / \mathrm{m}^{2}$ of face; however, the benefits can be significant, both in the short term, through reduction in contractual claims for excessive overbreak, and in the long term, through reduced maintenance costs. In some areas on the A82 cuttings, the highway alignment runs parallel with the line of the strike of the foliation planes in the micaschist. At these locations, consideration was given to eliminating the presplit by cutting the rock back to the natural planes which coincided with the design slope of the final face. However, the decision was taken to presplit at all locations, and while overbreak took place in some areas behind the presplit plane and on to a natural plane, we believe it would have been significantly greater if bulk blasting alone had been permitted.

93. While Dr O'Reilly has stressed the benefits of presplitting, we also wish to highlight the importance of slope design based on joint mapping to ensure that the final face is inherently stable. Without such an approach there are liable to be long-term maintenance problems even if presplitting is specified.

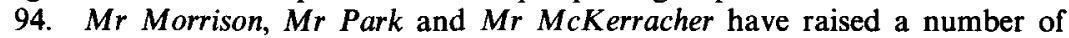
points in respect of presplit blasting. There is always a tendency for drill rods to dip into the foliation; on Rubha Mor cut this was particularly noticeable where the 1 in 1 design slope gave rise to a significant gravity induced deviation on the drill bit, with the result that the face was outside of specification tolerances on occasion, although it was still well formed. In these instances, the face was closely examined to ensure that design stability was being maintained and that critical planes had not been undercut. We do not consider it practical to adjust the angle of drilling at the top of each hole, as this would require a continual reassessment on site of drill rod deviation, the amount of which will be constantly changing with the highway alignment and rock conditions. It is good practice to carry out a trial presplit panel, parallel with the design face, on commencement of any cutting. This can be used to make final adjustments to drill rod angle, spacing and charge weights before the main production work.

95. Mr McKerracher has pointed out the difference in effectiveness of presplitting when down-the-hole hammer rigs are used instead of drifter rigs. The other recent introduction, which has assisted greatly in the setting-out of presplit holes, and hence final face tolerance, is the drill orientation device mentioned in $\S 42$ of the Paper.

96. Mr Carson has raised an important point regarding the quality of the rock and its potential for degradation in the underwater embankments. The physical 
properties of the rock were found to improve north of Inverbeg and, therefore, by constructing the Camus to Hollybank section first, the better quality rock was used for the advance earthworks in the deepwater banks. The main area of concern was in the zone around loch water level, the anticipated $3 \mathrm{~m}$ variation in the water level between the winter and summer periods resulting in a fluctuating air/water mixture which could hasten degradation at this location. However, the entire length of the embankments was protected by rip-rap around this zone, the better quality rock from the excavations being used for this purpose. In addition there is a footpath situated on a berm on the embankments on the lochside of the road. Any degradation or loss of material will therefore affect this feature before the main road embankment, allowing remedial action to be taken to preserve the integrity of the highway. Magnesium sulphate durability tests were carried out on rock samples during the construction period and these indicated that the material was generally sound.

97. A number of questions have been raised by $\mathrm{Dr}$ Coats regarding the procedures for placing and monitoring of rockfill in the underwater embankments and on the details of the rock anchors. In order to place the rock accurately, the Contractor set out a series of marker buoys, thereby splitting the placing area into a number of panels. The barges were then directed to the appropriate panel being placed at any one time. Monitoring of the fill profile was carried out on a weekly basis by the resident engineering staff, using EDM equipment on the shore sighting out to a target mounted on a dinghy equipped with a narrow beam echo sounder. Radio communication equipment between shore and dinghy enabled the boat to be brought in on a section line, and the distance off-shore to be marked on the echo sounder chart at appropriate intervals. Interpretation was then completed in the office. Any underfilling was made good by further barge placement; however, no attempt was made to trim back overfilling, in view of the obvious difficulties with such an operation.

98. The rock dowels used at Rubha Mor were $25 \mathrm{~mm}$ diameter, and were normally $3 \mathrm{~m}$ long. Couplings were provided to enable them to be extended beyond this if necessary. The rock anchors were between 10 and $12 \mathrm{~m}$ in total length of which the fixed anchor length was $4 \mathrm{~m}$. The end plates were bitumen painted but otherwise were left exposed. In spite of this, a close look at the rock face is required to see the anchor heads, and it is not felt that they will become any more obtrusive in the future.

\section{Reference}

12. MARKs R. J. et al. Aspects of civil engineering contract procedure. Pergamon Press, Oxford, edns 1, 2 and 3. 